\title{
Establishment of markerless gene deletion tools in thermophilic Bacillus smithii and construction of multiple mutant strains
}

\author{
Elleke F Bosma ${ }^{1}$, Antonius H P van de Weijer ${ }^{1}$, Laurens van der Vlist ${ }^{1}$, Willem M de Vos ${ }^{1}$, John van der Oost ${ }^{1}$ \\ and Richard van Kranenburg ${ }^{1,2^{*}}$ (B)
}

\begin{abstract}
Background: Microbial conversion of biomass to fuels or chemicals is an attractive alternative for fossil-based fuels and chemicals. Thermophilic microorganisms have several operational advantages as a production host over mesophilic organisms, such as low cooling costs, reduced contamination risks and a process temperature matching that of commercial hydrolytic enzymes, enabling simultaneous saccharification and fermentation at higher efficiencies and with less enzymes. However, genetic tools for biotechnologically relevant thermophiles are still in their infancy. In this study we developed a markerless gene deletion method for the thermophile Bacillus smithii and we report the first metabolic engineering of this species as a potential platform organism.
\end{abstract}

Results: Clean deletions of the IdhL gene were made in two B. smithii strains (DSM $4216^{\top}$ and compost isolate ET 138) by homologous recombination. Whereas both wild-type strains produced mainly L-lactate, deletion of the $/ \mathrm{dhL}$ gene blocked L-lactate production and caused impaired anaerobic growth and acid production. To facilitate the mutagenesis process, we established a counter-selection system for efficient plasmid removal based on lacZ-mediated X-gal toxicity. This counter-selection system was applied to construct a sporulation-deficient B. smithii $\Delta / d h L \Delta$ sigF mutant strain. Next, we demonstrated that the system can be used repetitively by creating B. smithii triple mutant strain ET $138 \Delta / d h L \Delta$ sigF $\Delta p d h A$, from which also the gene encoding the $\alpha$-subunit of the E1 component of the pyruvate dehydrogenase complex is deleted. This triple mutant strain produced no acetate and is auxotrophic for acetate, indicating that pyruvate dehydrogenase is the major route from pyruvate to acetyl-CoA.

Conclusions: In this study, we developed a markerless gene deletion method including a counter-selection system for thermophilic B. smithii, constituting the first report of metabolic engineering in this species. The described markerless gene deletion system paves the way for more extensive metabolic engineering of $B$. smithii. This enables the development of this species into a platform organism and provides tools for studying its metabolism, which appears to be different from its close relatives such as B. coagulans and other bacilli.

Keywords: Bacillus smithii, Thermophile, Lactate dehydrogenase, Sporulation, Pyruvate dehydrogenase, Counter-selection system

\section{Background}

Microbial conversion of biomass to fuels such as ethanol or hydrogen, or to green chemical building blocks such as

\footnotetext{
*Correspondence: r.van.kranenburg@corbion.com

1 Laboratory of Microbiology, Wageningen University, Dreijenplein 10, 6703 HB Wageningen, The Netherlands

Full list of author information is available at the end of the article
}

organic acids has gained increasing attention over the last decade $[1,2]$. Thermophilic microorganisms have several advantages over mesophilic organisms for use as microbial production hosts. Fermentation at high temperatures lowers cooling costs and contamination risks and increases product and substrate solubility [3-5]. Moreover, the optimum temperature of moderate thermophiles matches that of commercial hydrolytic enzymes, enabling 
simultaneous saccharification and fermentation at higher efficiencies and with less enzymes compared to mesophilic bacteria [6].

Despite the aforementioned advantages of thermophiles, mesophilic model organisms such as Escherichia coli and Saccharomyces cerevisiae are still preferred production organisms, as these are well-studied and genetic tools are available to enable their use as versatile platform organisms [7, 8]. Genetic tools for biotechnologically relevant thermophiles are recently emerging for different species, but most are still in their infancy or highly strain-specific. Several strictly and facultatively anaerobic thermophiles have been engineered for green chemical and fuel production, as has been reviewed recently $[9,10]$. Most engineering efforts in thermophiles have so far been directed at ethanol production, but recently also examples for chemical production have been shown such as Thermoanaerobacterium aotearoense for lactate production [11], Bacillus licheniformis for 2,3-butanediol production [12], and Bacillus coagulans for D-lactate production [13, 14]. The development of genetic tools for thermophilic organisms is crucial to fully understand their metabolic versatility and to establish a thermophilic production platform for green chemical and fuel production. For industrial applications, markerless gene deletions should be made such that no antibiotic resistance genes or other scars are introduced into the target genome. This is especially important when working with thermophilic organisms as the number of available markers is limited, requiring re-use of the marker $[9,10]$.

Recently, we isolated a thermophilic Bacillus smithii strain capable of degrading C5 and C6 sugars at a wide range of temperatures and $\mathrm{pHs}$ [15] and demonstrated electrotransformation of several B. smithii strains with plasmid pNW33n. In the current study, we developed a clean gene deletion method and counter-selection system for this species and applied this to create multiple markerless gene deletions both in the previously isolated B. smithii ET 138 [15] and in the type strain B. smithii DSM $4216^{\mathrm{T}}$.

\section{Results}

\section{Construction of markerless IdhL deletion mutants}

B. smithii ET 138 can be transformed with E. coli-Bacillus shuttle vector pNW33n with an efficiency of $5 \times 10^{3}$ colonies per $\mu$ g DNA [15]. To obtain mutants in strain ET 138, we planned to use a protocol similar to that used for Geobacillus thermoglucosidans (recently renamed from G. thermoglucosidasius [16]), which applies pNW33nderivatives as thermosensitive integration plasmid [17]. To create a markerless L-lactate dehydrogenase (ldhL) knockout strain from which the $l d h L$ gene was entirely deleted, $\sim 1,000$ bp regions flanking the $l d h L$ gene and including the start and stop codon were cloned and fused together in plasmid pNW33n. Double homologous recombination of this plasmid with the ET 138 chromosome will fuse the start and stop codons of the gene, thereby removing the entire gene in-frame without leaving any marker (Figure 1). B. smithii ET 138 was

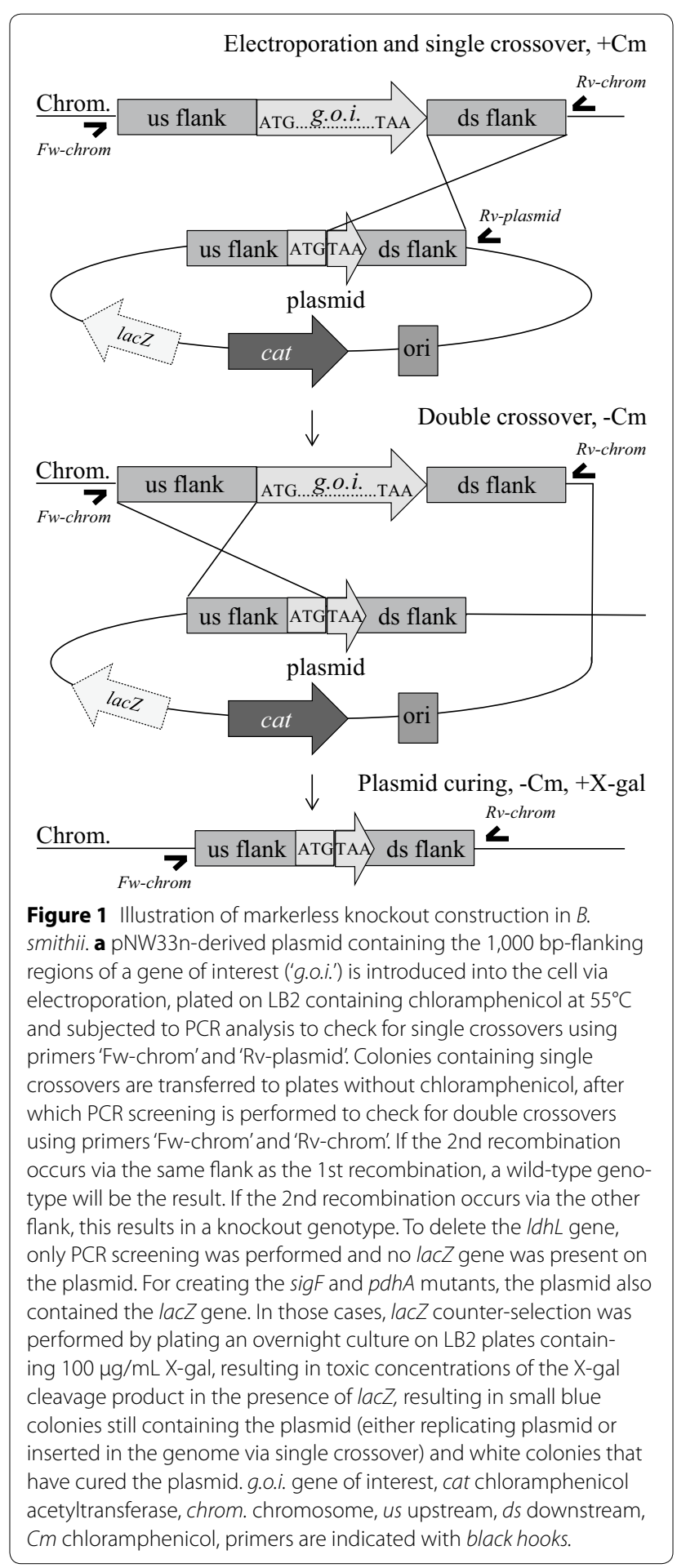


transformed with pWUR732 and colonies were transferred once at $55^{\circ} \mathrm{C}$ on LB2 plates containing chloramphenicol. Subsequent PCR analysis of 7 colonies already showed integration of the plasmid DNA without the temperature increase normally performed with thermosensitive integration systems [17]. A mixture of single crossover integrants via both upstream and downstream regions together with no-integration (either caused by replicating plasmids or randomly integrated plasmids) genotype was observed in one colony, one colony showed a mixture of downstream crossover and wild-type genotype, and five colonies showed no single crossovers but only wild-type genotype. Serial transfer of the colonies containing single crossovers in liquid medium combined with replica plating to identify double recombinants repeatedly resulted in only wild-type double crossover mutants. The mixed genotype persisted after several subculturings on plates containing 7 and $9 \mu \mathrm{g} / \mathrm{mL}$ chloramphenicol in an attempt to obtain pure genotypes. After four transfers, however, also a colony was found that contained a mixture of double crossover knockout genotype together with upstream single crossover and wild-type genotype. After this point, we added glycerol or acetate as carbon sources to allow for a metabolism with minimal impact of the $l d h L$ deletion. After streaking this colony to an LB2 plate containing $10 \mathrm{~g} / \mathrm{L}$ glycerol, colonies were obtained that had lost the wild-type genotype but contained a mixture of both single crossovers and a double crossover knockout genotypes. A pure double crossover knockout genotype was observed after two transfers on the more defined TVMY medium supplemented with acetate at $65^{\circ} \mathrm{C}$, creating strain ET $138 \Delta l d h L$ (Figure 2a).

Similar to strain ET 138, also type strain B. smithii DSM $4216^{\mathrm{T}}$ is transformable with pNW33n, with efficiencies of around $2 \times 10^{2}$ colonies per $\mu$ g DNA [15]. After transformation of strain DSM $4216^{\mathrm{T}}$ with $l d h L$-knockout construct pWUR733 and transfer of colonies to a new plate at $55^{\circ} \mathrm{C}$, PCR on 30 colonies showed mixtures of wildtype genotype and both single crossovers for all tested colonies. Contrary to what was observed with strain ET 138, several subculturings on TVMY supplemented with acetate at temperatures varying between 55 and $65^{\circ} \mathrm{C}$ did not result in a pure mutant genotype for derivatives of DSM $4216^{\mathrm{T}}$. However, after the substrate was changed from acetate to lactate, a pure double-crossover knockout colony was obtained after two transfers, creating strain DSM $4216^{\mathrm{T}} \Delta l d h L$ (Figure 2a).

\section{Establishment of a lacZ-counter-selection system}

Purifying the mixtures of plasmid integrated into the $B$. smithii genome via single and double crossovers during the construction of the $l d h L$-mutant strains required laborious PCR-screening. To simplify the screening procedure, a counter-selection tool was desirable to select against plasmid presence. A lacZ-counter-selection method has been described for the Gram-negative mesophile Paracoccus denitrificans, which is based on toxicity of high X-gal concentrations in the presence of $\beta$-galactosidase activity encoded by a lac $Z$-gene on the integration plasmid [18]. In the genome sequence of $B$. smithii ET 138 (unpublished data) no lacZ gene could be identified and the strain did not form blue colonies on plates containing X-gal. The lacZ gene from B. coagulans under control of the B. coagulans pta-promoter [14] was cloned into pNW33n, creating plasmid pWUR734. Introduction of pWUR734 into B. smithii ET 138 resulted in blue colonies in the presence of $25 \mathrm{mg} / \mathrm{L} \mathrm{X-gal.} \mathrm{When} B$. smithii ET 138 harbouring PWUR734 was grown in the

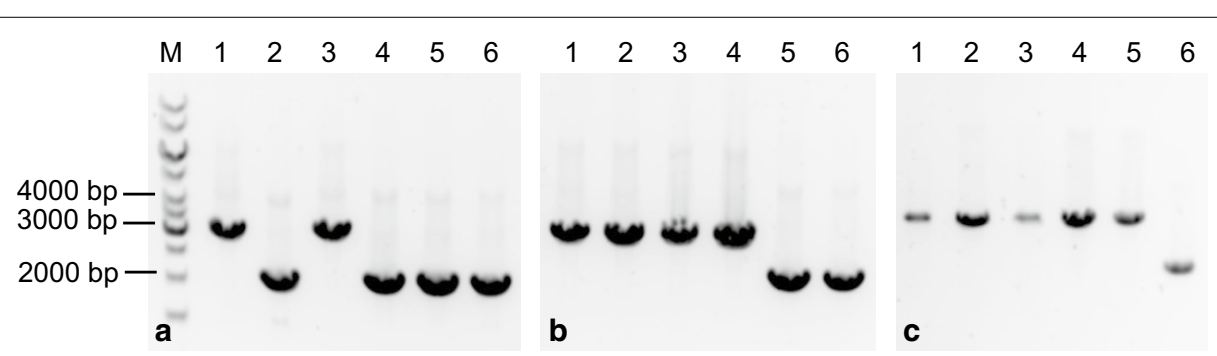

Figure 2 Gel-electrophoresis of PCR products from amplified target genes $/ d h L(\mathbf{a}), \operatorname{sig} F(\mathbf{b})$ and $p d h A(\mathbf{c})$. Order of strains in all three parts of the picture: M:Thermo Scientific $1 \mathrm{~kb}$ DNA ladder, 1 DSM 4216 wild-type, 2 DSM 4216 $\Delta /$ dhL, 3 ET 138 wild-type, 4 ET $138 \Delta / d h L, 5$ ET $138 \Delta / d h L \Delta$ sigF, 6 ET $138 \Delta / d h L \Delta$ sigF $\Delta p d h A$. The original gel pictures without cropping are provided in Additional files 1 (for $\mathbf{a}, \mathbf{b}$ ) and 2 (for $\mathbf{c}$ ). a Amplification of the region 1,000 bp up- and downstream of the IdhL gene using primers BG 3663 and 3669. The wild-type genotype results in a product of 3,036 bp, whereas the complete deletion of the IdhL gene is confirmed by a shift of the product to 2,094 bp. b Amplification of the region 1,000 bp up- and downstream of the sigF gene using primers BG 3990 and 3991. The wild-type genotype results in a product of 3,040 bp, whereas the complete deletion of the sigF gene is confirmed by a shift of the product to $2278 \mathrm{bp}$. c Amplification of the region 1,000 bp up-and downstream of the pdhA gene using primers BG 4563 and 4564 . The wild-type genotype results in a product of 3,390 bp, whereas the complete deletion of the $p d h A$ gene is confirmed by a shift of the product to 2,280 bp. 
presence of $100 \mathrm{mg} / \mathrm{L} \mathrm{X-gal,} \mathrm{the} \mathrm{blue} \mathrm{colonies} \mathrm{were} \mathrm{sig-}$ nificantly smaller than on $25 \mathrm{mg} / \mathrm{L}$, indicating toxicity of the X-gal cleavage product at high X-gal-concentrations (Additional file 3). To test the lacZ-counter-selection system, we chose sigF (spoIIAC) as the first knockout target gene, which is involved in the onset of Bacillus sporulation [19] (Figure 1). Transformation of strain ET 138 $\Delta l d h L$ with sigF-knockout vector pWUR735 containing the $\sim 1,000$ bp flanking regions of sigF yielded only blue and no white colonies, indicating functional expression of the B. coagulans pta::lacZ construct. Colony PCR on 8 colonies showed a mixture of single crossovers, wild-type and double-crossover knockout genotypes for six colonies and no single crossover but only double-crossover knockout and wild-type genotypes for two colonies. The latter two colonies, however, failed to grow after transfer to new LB2 plates. To obtain pure knockout strains, the counter-selection was applied by growing the colonies containing the mixed genotype of single and double crossovers overnight in $10 \mathrm{~mL} \mathrm{LB2}$ at $55^{\circ} \mathrm{C}$, after which dilution series were plated on LB2 supplemented with $100 \mathrm{mg} / \mathrm{L} \mathrm{X-gal}$. A mix of large white $(1-3 \mathrm{~mm})$ and small blue $(\leq 1 \mathrm{~mm})$ colonies was obtained for all six cultures (Additional file 3). Colony PCR on three white colonies from one of the cultures showed the presence of one pure knockout, one pure wild-type and one mix of wild-type and single-crossover genotypes. The colony showing the pure knockout genotype was inoculated into liquid LB2, after which DNA was isolated and PCR analysis confirmed the knockout genotype and absence of plasmid, creating strain ET $138 \Delta l d h L \Delta \operatorname{sig} F$ (Figure 2b).

\section{Construction of markerless triple mutant}

To evaluate whether the lacZ-counter-selection method can be used repeatedly to delete multiple genes and to evaluate acetate production pathways in B. smithii ET 138 , the $\alpha$-subunit of the E1 component of the pyruvate dehydrogenase complex $p d h A$ was targeted for deletion in strain ET $138 \Delta l d h L \Delta$ sigF using the lacZ-counterselection system. Based on genome analysis, pyruvate dehydrogenase appears to be the only route to acetylCoA in B. smithii (unpublished data). Therefore, the mutant strain was expected to be dependent on acetate to form acetyl-CoA and the medium was supplemented with acetate at all times after transformation. After transformation with $p d h A$-knockout vector pWUR737 containing the $\sim 1,000 \mathrm{bp}$ flanking regions of $p d h A$, cells were plated on TVMY supplemented with acetate and chloramphenicol. PCR on 15 colonies showed 13 colonies with a mixture of wild-type genotype together with both single crossovers, one colony with a mixture of wild-type and downstream crossover and 1 colony with a pure downstream crossover. After one transfer of the downstream crossover colony on LB2 medium supplemented with acetate without chloramphenicol, a colony was picked showing a mixture of downstream crossover, wild-type and double crossover knockout genotypes. This colony was subjected to the counter-selection protocol by plating on $100 \mathrm{mg} / \mathrm{L} \mathrm{X-gal} \mathrm{after} \mathrm{overnight} \mathrm{growth}$ in liquid LB2, resulting in a mixture of small blue and large white colonies. From the 32 white colonies tested in PCR, 12 still showed single crossovers, 16 returned to wild-type and 4 showed a clean double crossover knockout genotype, creating triple mutant ET $138 \Delta l d h L \Delta$ sigF $\Delta p d h A$ (Figure 2c).

\section{Confirmation of sporulation deficiency}

To confirm that strain ET $138 \Delta l d h L \Delta s i g F$ was unable to form spores, a Schaeffer-Fulton staining was performed (Figure 3). In the wild-type and the $l d h L$-mutant (Figure $3 \mathrm{a}, \mathrm{b}$ ) many spores were observed as indicated by the presence of green spheres, whereas no spores were observed in the $l d h L$-sigF-double mutant (Figure 3c). Pasteurisation of cultures of the wild-type and the $\Delta l d h L$ strain resulted in colony counts of $>5 \times 10^{5}$ and $3 \times 10^{5}$ per $\mathrm{mL}$ of cells, respectively. As expected, no colonies were observed after Pasteurisation of a culture of the $\Delta l d h L \Delta s i g F$ double mutant, while colony counts for the control treatment were $>5 \times 10^{5}$ per $\mathrm{mL}$ of cells for all three strains. Both assays confirm that the removal of the $s i g F$ gene results in a sporulation-deficient phenotype.

\section{Growth and production characteristics of mutant strains}

To evaluate growth and fermentation characteristics of the mutant strains, both strains ET 138 and DSM $4216^{\mathrm{T}}$ and all derived mutants were grown in tubes for $24 \mathrm{~h}$ under micro-aerobic conditions (Table 1). Whereas both ET 138 and DSM $4216^{\mathrm{T}}$ wild-type strains produced mainly L-lactate ( $\pm 95.5 \%$ of total products), the deletion of $l d h L$ reduced L-lactate production to values around or below the detection limit, as shown by HPLC analysis combined with D- and L-lactate-specific enzyme assays (Table 1). For both strains, the main product shifted from L-lactate to acetate, with minor amounts of D-lactate, malate and succinate and increased concentrations of pyruvate compared to the wild-types. Both the $\mathrm{OD}_{600}$ and the final product titre of the mutants were about half that of the wild-types. Strain ET $138 \Delta l d h L \Delta$ sigF did not show significant differences compared to strain ET $138 \Delta l d h L$ (Table 1). When the volume was increased from 25 to $40 \mathrm{~mL}$ in $50 \mathrm{~mL}$ tubes to further decrease the amount of oxygen present, the mutant strains showed even further reduced growth and production compared to the wild-type (data not shown). Similar results were obtained in $1 \mathrm{~L} \mathrm{pH}$ controlled reactors (Additional file 4). Complementation of strain ET $138 \Delta l d h L \Delta s i g F$ with its 

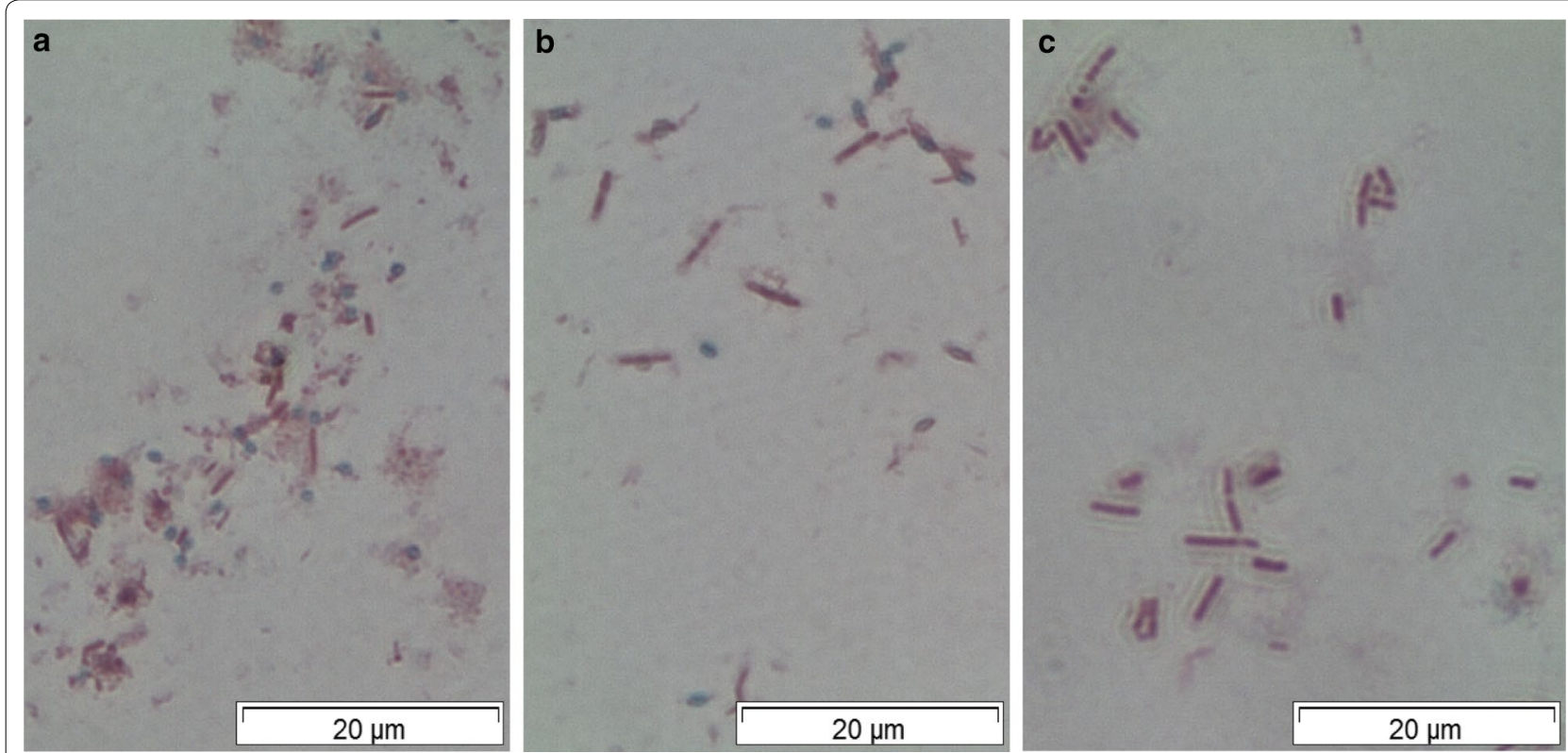

Figure 3 Schaeffer-Fulton staining on ET 138 wild-type and mutants. Cultures used were grown aerobically overnight in $\mathrm{LB} 2 \mathrm{medium}$ at $55^{\circ} \mathrm{C}$ and subsequently kept at room temperature for $24 \mathrm{~h}$, after which the staining was performed. Pink-stained cells indicate intact cells, whereas spores are green-blue. a strain ET 138 wild-type, in which sporulation is observed. b strain ET $138 \Delta / d h L$, in which sporulation is observed. c Strain ET 138 $\Delta / d h L \Delta s i g F$, where no sporulation is observed due to removal of the sigF gene.

Table 1 HPLC analysis of B. smithii ET 138 and DSM $4216^{\top}$ wild-type and mutant strains

\begin{tabular}{|c|c|c|c|c|c|c|c|c|}
\hline \multirow[t]{3}{*}{ Strain } & \multicolumn{8}{|c|}{ Products ( $\mathrm{mM}$ ) and measurement method } \\
\hline & \multicolumn{2}{|l|}{ Enzymatic } & \multicolumn{6}{|l|}{ HPLC } \\
\hline & L-lac & D-lac & Lac & Ace & Pyr & Mal & Suc & $\mathrm{OD}_{600}$ \\
\hline DSM 4216 wild-type & $15.85 \pm 2.22$ & $0.73 \pm 0.08$ & $20.67 \pm 1.25$ & $9.12 \pm 0.49$ & $0.21 \pm 0.11$ & $0.06 \pm 0.02$ & $0.27 \pm 0.10$ & $0.785 \pm 0.209$ \\
\hline DSM $4216 \Delta / d h L$ & $0.02 \pm 0.03$ & $4.11 \pm 0.86$ & $4.95 \pm 3.35$ & $12.40 \pm 3.16$ & $1.48 \pm 1.14$ & $0.35 \pm 0.07$ & $0.57 \pm 0.22$ & $0.466 \pm 0.057$ \\
\hline ET 138 wild-type & $20.55 \pm 4.09$ & $0.87 \pm 0.05$ & $26.18 \pm 7.66$ & $8.25 \pm 2.59$ & $0.78 \pm 0.31$ & $0.05 \pm 0.08$ & $0.61 \pm 0.16$ & $1.036 \pm 0.136$ \\
\hline ET $138 \Delta / d h L$ & $0.08 \pm 0.09$ & $1.08 \pm 0.32$ & $1.73 \pm 0.48$ & $14.33 \pm 5.54$ & $0.76 \pm 0.82$ & $0.33 \pm 0.15$ & $0.72 \pm 0.22$ & $0.581 \pm 0.289$ \\
\hline ET $138 \Delta / d h L \Delta s i g F$ & $0.06 \pm 0.05$ & $0.95 \pm 0.20$ & $1.58 \pm 0.62$ & $10.97 \pm 2.13$ & $0.70 \pm 0.41$ & $0.27 \pm 0.08$ & $0.60 \pm 0.16$ & $0.672 \pm 0.102$ \\
\hline ET $138 \Delta / d h L \Delta s i g F \Delta p d h A^{a}$ & $0.39 \pm 0.02$ & $11.17 \pm 0.47$ & $11.50 \pm 2.07$ & $-3.19^{\mathrm{a}} \pm 1.24$ & $8.26 \pm 0.82$ & $1.12 \pm 0.14$ & $1.85 \pm 0.37$ & $0.696 \pm 0.119$ \\
\hline ET $138 \Delta / d h L \Delta$ sigF + pWUR736 & $18.13 \pm 3.82$ & $1.11 \pm 0.40$ & $18.99 \pm 5.19$ & $7.32 \pm 1.33$ & $0.24 \pm 0.16$ & $0.08 \pm 0.18$ & $0.39 \pm 0.17$ & $0.831 \pm 0.200$ \\
\hline ET $138 \Delta / d h L \Delta s i g F+p N W 33 n$ & $0.14 \pm 0.04$ & $2.57 \pm 1.30$ & $3.17 \pm 1.13$ & $10.14 \pm 0.91$ & $0.94 \pm 0.53$ & $0.07 \pm 0.12$ & $0.36 \pm 0.08$ & $0.535 \pm 0.062$ \\
\hline ET 138 wild-type + pNW33n & $22.12 \pm 3.69$ & $0.69 \pm 0.10$ & $21.42 \pm 1.51$ & $5.63 \pm 1.15$ & $0.65 \pm 0.07$ & $0.05 \pm 0.12$ & $0.34 \pm 0.14$ & $0.849 \pm 0.076$ \\
\hline
\end{tabular}

Strains were grown in $25 \mathrm{~mL}$ TVMY supplemented with $10 \mathrm{~g} / \mathrm{L}$ glucose in $50 \mathrm{~mL}$ Greiner tubes at $55^{\circ} \mathrm{C}$ for $24 \mathrm{~h}$ after transfer from a $10 \mathrm{~mL}$-overnight culture. Dand L-lactate were distinguished via enzymatic assays, for which the lowest detection limit was $0.04 \mathrm{mM}$. The values shown are the results of three to fourteen independent experiments; numbers in italics are standard deviations.

L-lac L-lactate, D-lac D-lactate, Ace acetate, Pyr pyruvate, Mal malate, Suc succinate.

a These cultures were supplemented with $3 \mathrm{~g} / \mathrm{L}$ ammonium acetate.

native $l d h L$ gene and promoter expressed from pNW33n restored growth and L-lactate production to around wildtype levels (Table 1 ). Triple mutant ET $138 \Delta l d h L \Delta s i g F$ $\triangle p d h A$ was unable to grow without acetate supplementation and produced mainly $\mathrm{D}$-lactate and pyruvate. In this strain, very minor amounts of L-lactate $(0.39 \pm 0.02 \mathrm{mM})$ were observed. The final $\mathrm{OD}_{600}$ of this strain was on average comparable to the single and double mutant, but it showed less variation (Table 1 ).

\section{Discussion}

In this study, we developed an integration and counterselection system for markerless and consecutive gene deletion in thermophilic B. smithii. As L-lactate is the 
main fermentation product of $B$. smithii, the $l d h L$-gene was selected as the first knockout target in order to use this bacterium for the production of other products. Wang et al. reported a laborious screening procedure when constructing a $B$. coagulans $\Delta l d h L$ strain and indicated that only 1 in 5,000 colonies showed a knockout genotype after double crossover [13]. We observed a similar bias in B. smithii for the second crossover to result only in wild-type revertants. Furthermore, in single colonies we observed mixtures of either upstream or downstream single crossovers, wild-type and double crossover knockout genotype, even after several transfers targeted at purifying the colony. These mixed genotypes were not only observed for the $l d h L$ deletion, but also for the sigF and $p d h A$ deletions. For E. coli, such mixed genotypes have been described to occur during recombineering with linear DNA fragments, where it has been attributed to polyploidy, i.e. the existence of multiple chromosomes [20]. The copy number of the genome of our organism is currently unknown, but in general this number is likely to be higher when cells are grown in rich medium compared to minimal medium [20]. Transformation attempts with B. smithii grown on minimal medium were not successful (data not shown), but when cells were grown on minimal medium after crossovers had occurred, the purification of pure genotypes was relatively fast and easy. Switching to minimal medium to overcome mixed genotype issues might be a useful approach for other species as well.

In other thermophilic Bacilli, integration events were reported after the growth temperature had been increased $[17,21]$. Integration of the pNW33n-derived knockout plasmids in B. smithii without increasing the temperature indicates either a highly efficient recombination machinery, or plasmid instability already at $55^{\circ} \mathrm{C}$, although this temperature is regarded as permissive for pNW33n [17]. In both B. smithii strains, we observed very stable plasmid integration into the genome via single crossover recombination in colonies grown on plates without antibiotic pressure. As this integrational stability hampered purification of pure double crossover knockouts, a counter-selection method was developed to select against plasmid presence. Most frequently used counter-selection systems are based on either auxotrophy or antibiotic resistance. The lacZ-system is fundamentally different in enabling clean gene deletions and re-use of the marker without inducing auxotrophies, as has been demonstrated in the mesophilic $\alpha$-proteobacterium Paracoccus denitrificans [18]. The system can readily be used without making any prior gene deletions if the target strain does not possess $\beta$-glycosidase activity, as is the case in B. smithii. The system is based on the formation of toxic concentrations of inodxyl derivatives such as 5-bromo-4-chloro-3-indol, which is the cleavage product of 5-bromo-4-chloro-3-indolyl- $\beta$-D-galactopyranoside (X-Gal). Recently, indoxyl derivatives were shown to inhibit the growth of a wide variety of species growing at different temperatures, indicating that this system might be more widely applicable [22].

The lacZ-counter selection system considerably simplified the purification of single genotypes and enabled rapid and clean deletion of the sigF gene of ET $138 \Delta l d h L$ to create a sporulation-deficient strain. The system can be used repetitively to make multiple sequential deletions in the same strain as shown by the generated triple mutant ET $138 \Delta l d h L \Delta s i g F \Delta p d h A$. For both the sigF and the pdhA deletion, around $33 \%$ of the tested colonies were false positive after counter-selection, as they were white while still having a single crossover, which might be due to spontaneous disruption of the lac $\mathrm{Z}$ coding sequence or its promoter. Even with $33 \%$ false-positive white colonies, the screening for mutants is significantly simplified when using the lacZ-counter-selection system. A drawback of the system is that it does not force the double crossover in the direction of the knockout and can result in wild-type revertants. Whenever possible, cultivation conditions should be chosen such that the knockout cells will not have a large disadvantage over the wildtype cells. During this study, culturing in liquid medium resulted only in wild-type revertants, whereas knockouts were successfully obtained when the cultures were kept on plates. Supplementation of the plates with the gluconeogenic substrates acetate or lactate might have further reduced the disadvantage of knockouts over wild-types.

Removal of the sigF gene from B. smithii ET 138 resulted in a sporulation-deficient strain. Sporulation deficiency is desired in industrial settings both for practical and safety reasons. B. smithii was shown to have highly thermo-resistant spores $[23,24]$ and was found to be the most dominant species together with Geobacillus pallidus (recently renamed to Aeribacillus pallidus [16]) as highly thermostable spores in food. Both species were found to be non-cytotoxic [23]. The sigF-gene has been targeted successfully to create sporulation-deficient strains in several other Bacilli as well as in Clostridia, such as in B. coagulans [14], B. licheniformis [25, 26], B. subtilis [19] and Clostridium acetobutylicum [27].

Removal of the $l d h L$-gene from B. smithii ET 138 and DSM $4216^{\mathrm{T}}$ eliminated L-lactate production in both strains to values around or below the detection limit, which is similar to an $l d h L$-knockout of B. coagulans [13], a close relative of $B$. smithii. A lactate racemase was not found in the ET 138 genome, but the methylglyoxal pathway was annotated towards both D- and L-lactate (unpublished data) and this pathway is most likely the origin of the trace amounts of lactate observed in triple mutant ET $138 \Delta l d h L \Delta s i g F$ $\Delta p d h A$. Products such as acetoin, 2,3-butanediol, formate 
and ethanol have not been detected in any of the B. smithii mutant strains, while these were observed in $B$. coagulans $\Delta l d h L$ [13]. The absence of these products is in line with the absence of the acetolactate decarboxylase and pyruvateformate lyase genes from the $B$. smithii genomes (unpublished data). The $B$. smithii $l d h L$-mutants produced mainly acetate and some D-lactate and showed reduced growth and acid production under micro-aerobic conditions, which was restored by plasmid-based complementation in strain ET $138 \Delta l d h L \Delta s i g F$. The deficiency in anaerobic capacities is likely to be caused by the redox imbalance that results from the elimination of its main $\mathrm{NAD}^{+}$-regeneration pathway and the apparent lack of an alternative $\mathrm{NAD}^{+}$regeneration pathway, such as that to 2,3-butanediol. The lack of these pathways potentially makes $B$. smithii an interesting platform organism as only the $l d h L$ gene needs to be removed in order to eliminate production, after which the desired product pathways can be inserted.

Acetate was the main fermentation product of the $B$. smithii strains lacking the $l d h L$ gene, but the standard pathway to acetate via acetate kinase and phosphotransacetylase as well as a pyruvate-formate lyase gene are absent in the genomes of both strains ET 138 and DSM $4216^{\mathrm{T}}$ (unpublished data). To remove acetate production, the $p d h A$ gene encoding the $\alpha$-subunit of the E1 component of the pyruvate dehydrogenase complex was removed from strain ET $138 \Delta l d h L \Delta s i g F$. The resulting strain ET $138 \Delta l d h L \Delta s i g F \Delta p d h A$ did not produce acetate and was unable to grow without acetate supplementation. This implies that pyruvate dehydrogenase is the main enzyme responsible for pyruvate to acetyl-CoA, which is in line with the absence of a $p f l$ gene. Acetate utilization was previously suggested as a rescue pathway for redox balance in Lactococcus lactis $\Delta l d h L$ [28]. We tested acetate supplementation of strain ET $138 \Delta l d h L$ $\Delta s i g F$ but this did not improve growth or production (data not shown).

\section{Conclusion}

In this study, we established a clean gene deletion system for B. smithii using lacZ counter-selection. We constructed $l d h L$ mutants in the type strain B. smithii DSM $4216^{\mathrm{T}}$ and compost isolate strain ET 138. In the latter strain, triple mutant $\Delta l d h L \Delta s i g F \Delta p d h A$ was constructed, which does not produce L-lactate and acetate and is no longer capable of forming spores. Although further studies and modifications are needed to restore anaerobic growth and production capacities, the lacZcounter-selection system combined with mutant-specific culturing strategies provides a tool for the construction of markerless gene deletions in thermophilic B. smithii. This enables the development of this species into a platform organism and provides tools for studying its metabolism, which appears to be different from its close relatives such as B. coagulans and other Bacilli.

\section{Methods}

\section{Bacterial strains and growth conditions}

Strains used in this study are listed in Table 2. All $B$. smithii strains were routinely cultured at $55^{\circ} \mathrm{C}$ unless stated otherwise. E. coli $\mathrm{DH} 5 \alpha$ was grown at $37^{\circ} \mathrm{C}$. For growth experiments with strain ET $138 \Delta l d h L \Delta$ sigF $\Delta p d h A, 3 \mathrm{~g} / \mathrm{L}$ ammonium acetate was added to all media at all times. For all tube and plate cultures, carbon substrates were used in a concentration of $10 \mathrm{~g} / \mathrm{L}$ unless stated otherwise. Substrates and acetate were added separately as $50 \%$ autoclaved solutions after autoclavation of the medium. For plates, $5 \mathrm{~g} / \mathrm{L}$ Gelrite (Roth) was added. Unless indicated otherwise, chloramphenicol was added in concentrations of $25 \mu \mathrm{g} / \mathrm{mL}$ for $E$. coli and $7 \mu \mathrm{g} / \mathrm{mL}$ for B. smithii.

Thermophile Vitamin Medium with Yeast extract (TVMY) contained per L: $8.37 \mathrm{~g}$ MOPS; $0.5 \mathrm{~g}$ yeast extract (Roth), $100 \mathrm{~mL} 10 \times$ concentrated Eight Salt Solution (ESS), $1 \mathrm{~mL}$ filter sterile $1,000 \times$ concentrated vitamin solution, and $1 \mathrm{~mL}$ filter sterile $1,000 \times$ concentrated metal mix. ESS contained per L: $2.3 \mathrm{~g} \mathrm{~K}_{2} \mathrm{HPO}_{4} ; 5.1 \mathrm{~g}$ $\mathrm{NH}_{4} \mathrm{Cl} ; 50 \mathrm{~g} \mathrm{NaCl} ; 14.7 \mathrm{~g} \mathrm{Na}_{2} \mathrm{SO}_{4} ; 0.8 \mathrm{~g} \mathrm{NaHCO} ; 2.5 \mathrm{~g}$ $\left.\mathrm{KCl} ; 18.7 \mathrm{~g} \mathrm{MgCl}_{2} \cdot 6 \mathrm{H}_{2} \mathrm{O} ; 4.1 \mathrm{~g} \mathrm{CaCl}_{2} \cdot 2 \mathrm{H}_{2} \mathrm{O}\right) .1,000 \times$ concentrated metal mix contained per $\mathrm{L}: 16.0 \mathrm{~g} \mathrm{MnCl} 2 \cdot 6 \mathrm{H}_{2} \mathrm{O}$; $1.0 \mathrm{~g} \mathrm{ZnSO}_{4} ; 2.0 \mathrm{~g} \mathrm{H}_{3} \mathrm{BO}_{3} ; 0.1 \mathrm{~g} \mathrm{CuSO}_{4} .5 \mathrm{H}_{2} \mathrm{O} ; 0.1 \mathrm{~g}$ $\mathrm{Na}_{2} \mathrm{MoO}_{4} \cdot 2 \mathrm{H}_{2} \mathrm{O} ; 1.0 \mathrm{~g} \mathrm{CoCl}_{2} \cdot 6 \mathrm{H}_{2} \mathrm{O} ; 7.0$ g FeSO $4.7 \mathrm{H}_{2} \mathrm{O}$.

Table 2 B. smithii strains used in this study

\begin{tabular}{lll}
\hline Strain & Description & Reference/origin \\
\hline DSM $4216^{\top}$ & Wild-type, type strain of the species & DSMZ \\
DSM $4216^{\top} \Delta / d h L$ & DSM 4216 ${ }^{\top}$ with clean /dhL-deletion & This study \\
ET 138 & Wild-type, natural isolate & {$[15]$} \\
ET 138 $\Delta / d h L$ & ET 138 with clean $/ d h L$-deletion & This study \\
ET 138 $\Delta / d h L \Delta$ sigF & ET 138 $\Delta / d h L$ with clean sigF-deletion & This study \\
ET 138 $\Delta / d h L \Delta$ sigF $\Delta p d h A$ & ET 138 $\Delta / d h L \Delta$ sigF with clean $p d h A$-deletion & This study \\
\hline
\end{tabular}

DSMZ Deutsche Sammlung von Microorganismen und Zellkulturen, Germany. 
$1,000 \times$ concentrated vitamin mix contained per L: $0.1 \mathrm{~g}$ thiamine; $0.1 \mathrm{~g}$ riboflavin; $0.5 \mathrm{~g}$ nicotinic acid; $0.1 \mathrm{~g}$ panthothenic acid; $0.5 \mathrm{~g}$ pyridoxamine, $\mathrm{HCl} ; 0.5$ g pyridoxal, $\mathrm{HCl}$; $0.1 \mathrm{~g}$ D-biotin; $0.1 \mathrm{~g}$ folic acid; $0.1 \mathrm{~g}$-aminobenzoic acid; $0.1 \mathrm{~g}$ cobalamin. The $\mathrm{pH}$ of TVMY was set to 6.94 at room temperature and the medium was autoclaved for $20 \mathrm{~min}$ at $121^{\circ} \mathrm{C}$, after which vitamin solution, metal mix and substrate were added.

LB2 medium contained per L: 10 g tryptone (Oxoid), 5 g yeast extract (Roth), $100 \mathrm{~mL}$ ESS. The $\mathrm{pH}$ was set to 6.95 at room temperature and the medium was autoclaved for $20 \mathrm{~min}$ at $121^{\circ} \mathrm{C}$. For all mutant strains, vitamins and metals as described above for TVMY were also added to LB2.

To evaluate product profiles and growth, cells were inoculated from glycerol stock into $10 \mathrm{~mL}$ TVMY supplemented with $10 \mathrm{~g} / \mathrm{L}$ glucose in a $50 \mathrm{~mL}$ Greiner tube and grown overnight at $55^{\circ} \mathrm{C}$ and $150 \mathrm{rpm}$. Next morning, $250 \mu \mathrm{L}$ cells was transferred to $25 \mathrm{~mL}$ of the same medium in $50 \mathrm{~mL}$ Greiner tubes and incubated at $55^{\circ} \mathrm{C}$ and $150 \mathrm{rpm}$ for $24 \mathrm{~h}$, after which $\mathrm{OD}_{600}$ was measured and fermentation products were analysed.

\section{Plasmid construction}

Plasmids and primers used in this study are shown in Tables 3 and 4. Genomic DNA from B. smithii strains was isolated using the MasterPure ${ }^{\mathrm{Tm}}$ Gram Positive DNA Purification Kit (Epicentre). E. coli DH5 $\alpha$ heat shock transformation was performed according to standard procedures [29]. All restriction enzymes and polymerases were obtained from Thermo Scientific. PCR products were gel-purified from a $0.8 \%$ agarose gel using the Zymoclean $^{\text {TM }}$ Gel DNA Recovery Kit.

For the construction of ET 138 ldhL-knockout vector pWUR732, the flanking regions of the $l d h L$ gene were PCR-amplified from genomic DNA using primers BG3633 and BG3637 (upstream, 923 bp) and BG3638 and BG3636 (downstream, $928 \mathrm{bp}$ ) using Phusion polymerase. DSM $4216^{\mathrm{T}} l d h L$-knockout vector pWUR733 was created using the same primers, resulting in a $913 \mathrm{bp}$ upstream region and 935 downstream. After gel-purification, an overlap extension PCR was performed in which the upstream and downstream region were fused using primers BG3633 and BG3636, making use of the complementary overhang in primers BG3637 and BG3638. The resulting PCR product was again gel-purified and subsequently cut with EcoRI and SalI using the restriction sites included in primers BG3633 and BG3636, as was plasmid pNW33n. After restriction, the fusion product and $\mathrm{pNW} 33 \mathrm{n}$ were ligated using T4 ligase (Thermo Scientific) for $1 \mathrm{~h}$ at room temperature and transformed to heat shock competent $E$. coli DH $5 \alpha$.

To create lacZ-containing plasmid pWUR734, primers BG3887 and BG3888 were used to generate the B. coagulans $\mathrm{P}_{p t a}$-lacZ promoter-gene fusion fragment by PCR using plasmid pPTA-LAC as template [14]. The resulting fragment was cloned into pNW33n using SacI and BspHI and transformed to heat shock competent E. coli DH5 $\alpha$.

The ET 138 sigF flanking regions fragments of the knockout-plasmid pWUR735 were generated by using primers BG3971 and BG3972 (downstream, $970 \mathrm{bp}$ ) and BG3973 and BG3974 (upstream, 976 bp). The flanks were fused by PCR using primers BG3971 and BG3974, cloned into pWUR734 using EcoRI and SalI and transformed to heat shock competent $E$. coli DH5 $\alpha$. Plasmid pWUR737 containing the $p d h A$ flanks in pWUR734 was constructed in a similar manner, using primers BG4522 and BG4523 to generate the $p d h A$ upstream flank (1011 bp) and BG4524 and BG4525 to generate the pdhA downstream flank (1037 bp) by PCR. The flanks were fused by PCR using primers BG4522 and 4525 and cloned into pWUR737 using EcoRI and SalI.

For construction of ET 138 ldhL-complementation plasmid pWUR736, the $l d h L$ gene with its native promotor (until 525 bp upstream of the gene) was amplified from the ET 138 genome using primers BG4534 and BG4535. The fragment was cloned into pNW33n using HindIII and XbaI.

Transformed E. coli DH5 $\alpha$ colonies were picked and inoculated into $5 \mathrm{~mL} \mathrm{LB}$ containing $25 \mu \mathrm{g} / \mathrm{mL}$

Table 3 Plasmids used in this study

\begin{tabular}{lll}
\hline Plasmid & Description & Reference/origin \\
\hline pNW33n & E. coli-Bacillus shuttle vector, cloning vector, Cm & BGSC \\
pWUR732 & IdhL-KO vector for ET138: pNW33n + IdhL-flanks & This study \\
pWUR733 & IdhL-KO vector for DSM 4216: pNW33n + IdhL-flanks & This study \\
pWUR734 & pNW33n + B. coagulans P pta-lacZ & [14]; this study \\
pWUR735 & sigF-KO vector for ET138: pWUR734 + ET 138 sigF-flanks & This study \\
pWUR736 & IdhL-restoration vector for ET138: pNW33n + IdhL-gene from ET 138 under its native promoter (525 bp us of IdhL) & This study \\
pWUR737 & pdhA-KO vector for ET138: pWUR734 + ET 138 pdhA -flanks & This study
\end{tabular}

$\mathrm{Cm}^{R}$ chloramphenicol resistance gene, KO knockout, BGSC Bacillus Genetic Stock Centre, USA, us upstream, bp base pairs. 
Table 4 Primers used in this study

\begin{tabular}{|c|c|c|}
\hline BG nr & Sequence $5^{\prime}-3^{\prime}$ & Purpose \\
\hline 3464 & AACTCTCCGTCGCTATTGTAACCA & Check plasmid presence \\
\hline 3465 & TATGCGTGCAACGGAAGTGAC & Check plasmid presence \\
\hline 3633 & GCCGTCGACCATTTGCAGTAGGTCTCGATC & IdhL-us-Fw \\
\hline 3636 & GCCGAATTCTAGGTCACCAAAGACGAAATTG & IdhL-ds-Rv \\
\hline 3637 & GCTCCCTTTGTATGGTCGTTTACATAATAAGAAACTCCTTTCGTCATTTC & IdhL-us-Rv \\
\hline 3638 & GAAATGACGAAAGGAGTTTCTTATTATGTAAACGACCATACAAAGGGAGC & IdhL-ds-Fw \\
\hline 3664 & AGGGCTCGCCTTTGGGAAG & Int. check, in plasmid \\
\hline 3663 & ATCGCGTGAAATGTTCTAATGG & Int. check IdhL on chr.-Fw \\
\hline 3669 & AACCGATGCCGTTGATTAAAG & Int. check IdhL on chr.-Rv \\
\hline 3887 & GCCGAGCTCTTGCCGGAATTCTTTCAC & pta-lacZ-Fw \\
\hline 3888 & GCCTCATGACTATTTTTCAATTACCTGCAAAATTTTTC & pta-lacZ-Rv \\
\hline 3971 & GCCGAATTCAGCTAATCTTGTTGACGGTTTTC & sigF-ds-Fw \\
\hline 3972 & GTAACTAAGGAGTCGTGCCTTAACGATTCATGTGCTTTTTTTTG & sigF-ds-Rv \\
\hline 3973 & CAAAAAAAAGCACATGAATCGTTAAGGCACGACTCCTTAGTTAC & sigF-us-Fw \\
\hline 3974 & GCCGTCGACCTCTGATTTAGAAGATGGAGGTTTT & sigF-us-Rv \\
\hline 3990 & CGCCTATTCTTTTCGCTAAAATCGG & Int. check sigF on chr.-Fw \\
\hline 3991 & ATAAGCTGCAGAGGGATATACAC & Int. check sigF on chr.-Rv \\
\hline 4534 & GCCTCTAGAATTGGTCATTTGATTAGA & ET $138 / d h L+$ prom.-Fw \\
\hline 4535 & GCCAAGCTTTTAAGAAAGTACTTTATT & ET $138 / d h L+$ prom.-Rv \\
\hline 4522 & GCCGAATTCGAGGTACATAGCCCGGAATC & pdhA-us-Fw \\
\hline 4523 & GTCATTTGCGGCATGGCTTACATTCGTGTCACCTCTTCCTTTC & pdhA-us-Rv \\
\hline 4524 & GAAAGGAAGAGGTGACACGAATGTAAGCCATGCCGCAAATGAC & $p d h A-d s-F w$ \\
\hline 4525 & GCCGTCGACCATCCTCATAACGGCCATCC & $p d h A-d s-R v$ \\
\hline 4563 & GTTTCACATACCATTTAACGATTT & Int. check pdhc on chr.-Rv \\
\hline 4564 & GTCAATAGGTGCAAATGGATTTTC & Int. check pdhc on chr.-Fw \\
\hline
\end{tabular}

us upstream flanking region, $d s$ downstream flanking region, Fw forward primer, Rv reverse primer, Int. integration, chr. chromosome, prom. promoter.

chloramphenicol, after which plasmids were isolated using the GeneJET Plasmid Miniprep Kit (Thermo Scientific) and the integrity of the cloned fragments was confirmed by DNA sequencing (GATC, Germany). Plasmids for transforming ET 138 and DSM $4216^{\mathrm{T}}$ were extracted from DH5 $\alpha$ via maxiprep isolation (Genomed Jetstar 2.0).

\section{Competent cell preparation and electroporation of $B$. smithii}

B. smithii was transformed by electroporation as described previously [15]. In brief, B. smithii cells were grown overnight at $55^{\circ} \mathrm{C}$ in $10 \mathrm{~mL} \mathrm{LB} 2$ in a $50 \mathrm{~mL}$ Greiner tube and next morning diluted to an $\mathrm{OD}_{600}$ of 0.08 in $100 \mathrm{~mL} \mathrm{LB} 2$ in a $500 \mathrm{~mL}$ baffled Erlenmeyer flask $\left(\mathrm{DSM} 4216^{\mathrm{T}}\right.$ ) or $1 \mathrm{~L}$ bottle (ET 138). Cells were grown to an $\mathrm{OD}_{600}$ between 0.45 and 0.65 and made competent as described previously [30]. Electroporation was performed applying settings of $2.0 \mathrm{kV}, 25 \mu \mathrm{F}$ and $400 \Omega$ in a $2 \mathrm{~mm}$ cuvette for ET 138 and $1.5 \mathrm{kV}, 25 \mu \mathrm{F}$ and $600 \Omega$ in a $1 \mathrm{~mm}$ cuvette for DSM4216 ${ }^{\mathrm{T}}$ (ECM 630 electroporator, GeneTronics Inc.). 2-5 $\mu \mathrm{g}$ plasmid DNA was added to the cells for electroporation and LB2 medium was used for recovery at $52^{\circ} \mathrm{C}$ for $3 \mathrm{~h}$. After overnight growth on LB2 plates containing $7 \mu \mathrm{g} / \mathrm{mL}$ chloramphenicol and in the case of lacZ-containing plasmids also $20 \mu \mathrm{g} / \mathrm{mL}$ $\mathrm{X}$-gal at $52^{\circ} \mathrm{C}$, several colonies were streaked to a fresh plate and grown overnight at $55^{\circ} \mathrm{C}$, after which colony PCR was performed to confirm the presence of the plasmid and check for integration.

\section{B. smithii colony PCR}

Colony PCR on B. smithii was performed using the InstaGene Matrix protocol (BioRad) with several modifications: colonies were picked and resuspended in $200 \mu \mathrm{L}$ MQ water in a $1.5 \mathrm{~mL}$ Eppendorf tube and centrifuged at 13,200 rpm for $2 \mathrm{~min}$. The supernatant was removed, $100 \mu \mathrm{L}$ InstaGene Matrix was added to the pellet and this was incubated at $55^{\circ} \mathrm{C}$ for $30 \mathrm{~min}$. After this, the mixtures were vortexed at high speed for $10 \mathrm{~s}$ and incubated at $99^{\circ} \mathrm{C}$ in a heat block (Eppendorf) for $8 \mathrm{~min}$, vortexed again for $10 \mathrm{~s}$ and centrifuged at 13200 for $3 \mathrm{~min}$. Subsequently, $10 \mu \mathrm{L}$ of the resulting supernatant was used per $25 \mu \mathrm{L}$ PCR reaction and the remainder was stored at $-20^{\circ} \mathrm{C}$ for later use. 


\section{Construction of $B$. smithii ET 138 and DSM $4216^{\top}$ IdhL mutants}

B. smithii ET 138 was made competent and electroporated with pWUR732. After transformation, colonies were subjected to colony PCR using primers BG3663 and BG3669 to distinguish double crossover wild-type and knockout genotypes, BG3664 and BG3669 to check chromosomal integration of the plasmid and BG3464 and BG3465 to check plasmid presence. A colony showing both upstream and downstream integration as well as wild-type genotype was picked and streaked to a fresh LB2 plate supplemented with $7 \mu \mathrm{g} / \mathrm{mL}$ chloramphenicol and grown overnight at $55^{\circ} \mathrm{C}$, which was repeated one more time at $7 \mu \mathrm{g} / \mathrm{mL}$ chloramphenicol and then twice at $9 \mu \mathrm{g} / \mathrm{mL}$ chloramphenicol. From the last plate, a colony was picked that showed both wild-type and double-crossover knockout genome, as well as a single crossover via the upstream region. After overnight growth on LB2 supplemented with $7 \mu \mathrm{g} / \mathrm{mL}$ chloramphenicol and $1 \%$ glycerol at $55^{\circ} \mathrm{C}$, a colony was picked that did no longer show the wild-type genotype. This colony was transferred twice on TVMY supplemented with $50 \mathrm{mM}$ ammonium acetate at $65^{\circ} \mathrm{C}$, resulting in a pure knockout genotype. Genomic DNA isolation was performed on liquid cultures grown overnight in TVMY containing $50 \mathrm{mM}$ ammonium acetate to confirm the knockout genotype and lack of plasmid. The PCR product from primers BG3663 and BG3669 was purified (Zymo DNA Clean \& Concentrator) to confirm correct deletion of the gene by sequencing.

B. smithii DSM4216 ${ }^{\mathrm{T}}$ was made competent and transformed with pWUR733, colonies were streaked to a new LB2 plate with $7 \mu \mathrm{g} / \mathrm{mL}$ chloramphenicol and checked for integrations as described for B. smithii ET 138. A colony showing wild-type genotype as well as both upstream and downstream integration was picked and streaked to a fresh LB2 plate supplemented with $9 \mu \mathrm{g} / \mathrm{mL}$ chloramphenicol and grown overnight at $55^{\circ} \mathrm{C}$. Subsequently, it was transferred 3 more times on the same medium at $55^{\circ} \mathrm{C}$ and once at $65^{\circ} \mathrm{C}$, after which 1 transfer was performed on LB2 containing $7 \mu \mathrm{g} / \mathrm{mL}$ chloramphenicol and $1 \%(\mathrm{v} / \mathrm{v})$ glycerol at $55^{\circ} \mathrm{C}$. Next, the colony was transferred several times on TVMY containing $50 \mathrm{mM}$ ammonium acetate at $55^{\circ} \mathrm{C}$ and $65^{\circ} \mathrm{C}$. During the whole procedure, colony PCR using the above-mentioned primers was performed and only colonies showing single crossover (combined with wild-type genotype) were transferred. Subsequently, a colony showing double crossover knockout genotype mixed with wild-type and single crossovers was purified by transferring to TVMY containing $50 \mathrm{mM}$ ammonium acetate 5 more times at $60^{\circ} \mathrm{C}$ and then 2 times on TVMY containing $50 \mathrm{mM}$ lactate. Genomic DNA isolation was performed on liquid cultures grown overnight in TVMY containing $50 \mathrm{mM}$ lactate to confirm the knockout genotype and lack of plasmid. The PCR product from primers BG3663 and BG3669 was purified (Zymo DNA Clean \& Concentrator) to confirm correct deletion of the gene by sequencing.

\section{Construction of $B$. smithii ET $138 \Delta / d h L \Delta s i g F$ mutant using lac $Z$ counter-selection}

After transformation of $B$. smithii ET $138 \Delta l d h L$ with plasmid pWUR735, blue colonies were transferred to new LB2 plates supplemented with $7 \mu \mathrm{g} / \mathrm{mL}$ chloramphenicol twice at $55^{\circ} \mathrm{C}$. Subsequently, colony PCR was performed using primers BG3990 and BG3991 to distinguish double crossover wild-type and knockout genotypes, and primers BG3990 and BG3664 to check chromosomal integration of the plasmid and BG3464 and BG3465 to check plasmid presence. Several colonies showing a mixture of single crossovers, wild-type and double-crossover knockout genotype were transferred to $10 \mathrm{~mL} \mathrm{LB2}$ in $50 \mathrm{~mL}$ tubes and grown overnight at $55^{\circ} \mathrm{C}$, after which dilution series were plated on LB2 supplemented with $100 \mu \mathrm{g} / \mathrm{mL}$ X-gal. After overnight growth, white colonies were picked and transferred twice for overnight growth at $55^{\circ} \mathrm{C}$ on LB2 plates, after which colony PCR was performed to distinguish wild-type from double-crossover knockout genotype. Genomic DNA isolation was performed on liquid culture grown overnight in LB2 to confirm the knockout genotype and lack of plasmid. The resulting PCR product was purified (Zymo DNA Clean \& Concentrator) to confirm correct deletion of the gene by sequencing and glycerol stocks were made.

\section{Construction of $B$. smithii ET $138 \Delta / d h L \Delta$ sigF $\Delta p d h A$ mutant using lac $Z$ counter-selection}

B. smithii ET $138 \Delta l d h L \Delta s i g F$ was transformed with plasmid pWUR737 and recovery and plating was performed at $52^{\circ} \mathrm{C}$ on TVMY containing $50 \mathrm{mM}$ ammonium acetate, $7 \mu \mathrm{g} / \mathrm{mL} \mathrm{Cm}$ and $20 \mu \mathrm{g} / \mathrm{mL}$ X-gal. Next day, blue colonies were streaked to new plates containing the same medium without X-gal and grown overnight, after which colony PCR was performed using primers BG4563 and BG4564 to distinguish double crossover wild-type and knockout genotypes and BG4564 and BG3664 to check chromosomal integration of the plasmid. Several colonies showing either single crossover and/or double crossover were transferred to fresh TVMY containing $50 \mathrm{mM}$ ammonium acetate plates containing antibiotics and grown overnight at $52^{\circ} \mathrm{C}$, after which the same colony PCR was performed on the new colonies. One colony that showed only downstream crossover, whereas the others showed only upstream crossover, did not grow any further on TVMY containing $50 \mathrm{mM}$ ammonium acetate and thus was transferred to LB2 containing $50 \mathrm{mM}$ ammonium acetate plates without antibiotics and 
subjected again to colony PCR after overnight growth. One colony showing a strong double crossover knockout band was transferred to LB2 containing $50 \mathrm{mM}$ ammonium acetate and grown overnight, after which it was inoculated into $10 \mathrm{~mL}$ liquid LB2 containing $50 \mathrm{mM}$ ammonium acetate in a $50 \mathrm{~mL}$ tube and grown overnight at $55^{\circ} \mathrm{C}$ and $150 \mathrm{rpm}$. Subsequently, dilution series were plated on LB2 containing $50 \mathrm{mM}$ ammonium acetate supplemented with $100 \mu \mathrm{g} / \mathrm{mL} \mathrm{X-gal.} \mathrm{After} \mathrm{overnight}$ growth, white colonies were streaked to a new plate LB2 containing $50 \mathrm{mM}$ ammonium acetate and subjected to colony PCR. Several colonies showing pure knockout genotype were inoculated into $10 \mathrm{~mL}$ LB2 containing $50 \mathrm{mM}$ ammonium acetate and grown overnight. Genomic DNA isolation was performed on liquid cultures grown overnight in LB2 to confirm the knockout genotype and lack of plasmid, after which the resulting PCR product was purified (Zymo DNA Clean \& Concentrator) to confirm correct deletion of the gene by sequencing.

\section{Sporulation assays}

For the Schaeffer-Fulton staining [31], B. smithii strains ET 138 wild-type, ET $138 \Delta l d h L$ and ET $138 \Delta l d h L$ $\Delta s i g F$ were grown aerobically overnight in LB2 medium at $55^{\circ} \mathrm{C}$ and subsequently kept at room temperature for $24 \mathrm{~h}$, after which a droplet of the cell culture was added to a microscopy slide and allowed to air-dry. The sample was heat-fixed above a gas flame and covered with a piece of absorbance paper, after which the slide was flooded with $50 \mathrm{~g} / \mathrm{L}$ malachite green (4-[(4-dimethylaminophenyl)phenyl-methyl]-N,N-dimethylaniline) and heated to steam twice. The absorbance paper was removed and the slide was washed with tap water, after which it was flooded with $25 \mathrm{~g} / \mathrm{L}$ safranin for $30 \mathrm{~s}$, washed with tap water, dried with paper and evaluated under the microscope (Carl Zeiss Primo Star 1000x magnification with Olympus Soft Imaging Solutions Camera and analySIS 5.0 imaging software).

For the pasteurization assay, strains ET 138 wild-type, ET $138 \Delta l d h L$ and ET $138 \Delta l d h L \Delta s i g F$ were grown for $24 \mathrm{~h}$ in $10 \mathrm{~mL} \mathrm{LB} 2$ in a $50 \mathrm{~mL}$ Greiner tube. $1 \mathrm{~mL}$ culture was transferred to a $1.5 \mathrm{~mL}$ reaction tube in duplicate, of which one tube was incubated at $60^{\circ} \mathrm{C}$ for $45 \mathrm{~min}$ as a control and one at $85^{\circ} \mathrm{C}$ for $45 \mathrm{~min}$. After this, a $100 \times$ dilution was plated on LB2 and incubated overnight at $55^{\circ} \mathrm{C}$, after which colonies were counted.

\section{Analytical methods}

Sugar and fermentation products were quantified using a high-pressure liquid chromatography (HPLC) system (Thermo) equipped with a UV1000 detector operating on $210 \mathrm{~nm}$ and a RI-150 $40^{\circ} \mathrm{C}$ refraction index detector and containing a Shodex RSpak KC-811cation-exchange column. The mobile phase consisted of $5 \mathrm{mM} \mathrm{H}_{2} \mathrm{SO}_{4}$ and the column was operated at $0.8 \mathrm{~mL} / \mathrm{min}$ and $80^{\circ} \mathrm{C}$. All samples were diluted 1:1 with $10 \mathrm{mM}$ DMSO in $0.04 \mathrm{~N}$ $\mathrm{H}_{2} \mathrm{SO}_{4}$. L-lactate and D-lactate kits from Megazyme (K-LATE and K-DATE) were used to distinguish between $\mathrm{L}$-lactate and D-lactate according to the manufacturer's protocol.

\section{Additional files}

Additional file 1: This file shows the original gel for Figure $2 \mathrm{~A}$ and $\mathrm{B}$. It is the same gel as in Figure C/additional file 2, but with a shorter exposure time.

Additional file 2: This file shows the original gel for Figure $2 \mathrm{C}$. It is the same gel as in Figure A-B/additional file 1, but with a longer exposure time.

Additional file 3: $B$. smithii $\Delta / d h L-\Delta$ sigF after counter-selection on plates containing $100 \mu \mathrm{g} / \mathrm{mL} X$-gal. This figure shows the difference in colony size on $100 \mu \mathrm{g} / \mathrm{mL}$ X-gal after lacZ counter-selection.

Additional file 4: Fermentation analysis of B. smithii ET 138 wild-type and mutant strains in $1 \mathrm{~L} \mathrm{pH}$-controlled bioreactors after $\pm 24 \mathrm{~h}$. This table shows fermentation data in $\mathrm{pH}$-controlled lab-scale reactors to supplement the data in tubes described in the main text.

\section{Authors' contributions}

EFB designed, executed and analysed the experiments and wrote the manuscript. AHPvdW participated in the design of the experiments, performed the experimental and analytical part of the growth experiments and revised the manuscript. LvdV constructed and analysed the sigF mutant, designed and performed the sporulation assays and was involved in revision of the manuscript. JvdO, WMdV and RvK participated in the design and co-ordination of the study and in revision of the manuscript. All authors read and approved the final manuscript.

\section{Author details}

${ }^{1}$ Laboratory of Microbiology, Wageningen University, Dreijenplein 10 , 6703 HB Wageningen, The Netherlands. ${ }^{2}$ Corbion, Arkelsedijk 46, 4206 AC Gorinchem, The Netherlands.

\section{Acknowledgements}

We thank Sjuul Hegger and Martinus J.A. Daas for technical assistance, Corbion (Gorinchem, NL) for kindly providing plasmid P pta-lacZ [14] and Dr. Ron Winkler from Dutch Technology Foundation STW for his involvement in an earlier phase of this work. This work was financially supported by Corbion.

\section{Compliance with ethical guidelines}

\section{Competing interests}

The authors declare that they have no competing interests. RvK is employed by the commercial company Corbion (Gorinchem, The Netherlands).

Received: 12 May 2015 Accepted: 18 June 2015

Published online: 07 July 2015

\section{References}

1. Werpy T, Petersen G, Aden A, Bozell J, Holladay J, White J et al (2004) Top value added chemicals from biomass. Volume 1-results of screening for potential candidates from sugars and synthesis gas. DTIC Document

2. Bozell JJ, Petersen GR (2010) Technology development for the production of biobased products from biorefinery carbohydrates-the US Department of Energy's "Top 10" revisited. Green Chem 12:539-554 
3. Bhalla A, Bansal N, Kumar S, Bischoff KM, Sani RK (2013) Improved lignocellulose conversion to biofuels with thermophilic bacteria and thermostable enzymes. Bioresour Technol 128:751-759

4. Ma K, Maeda T, You H, Shirai Y (2014) Open fermentative production of I-lactic acid with high optical purity by thermophilic Bacillus coagulans using excess sludge as nutrient. Bioresour Technol 151:28-35

5. Studholme DJ (2014) Some (bacilli) like it hot: genomics of Geobacillus species. Microb Biotechnol 8:40-48

6. Ou MS, Mohammed N, Ingram LO, Shanmugam KT (2009) Thermophilic Bacillus coagulans requires less cellulases for simultaneous saccharification and fermentation of cellulose to products than mesophilic microbial biocatalysts. Appl Biochem Biotechnol 155:379-385

7. Chen X, Zhou L, Kangming T, Kumar A, Singh S, Prior BA et al (2013) Metabolic engineering of Escherichia coli: A sustainable industrial platform for bio-based chemical production. Biotechnol Adv 31:1200-1223

8. Hong K-K, Nielsen J (2012) Metabolic engineering of Saccharomyces cerevisiae: a key cell factory platform for future biorefineries. Cell Mol Life Sci 69:2671-2690

9. Bosma EF, van der Oost J, de Vos WM, van Kranenburg R (2013) Sustainable production of bio-based chemicals by extremophiles. Curr Biotechnol 2:360-379

10. Taylor M, van Zyl L, Tuffin I, Leak D, Cowan D (2011) Genetic tool development underpins recent advances in thermophilic whole-cell biocatalysts. Microb Biotechnol 4:438-448

11. Yang X, Lai Z, Lai C, Zhu M, Li S, Wang J et al (2013) Efficient production of I-lactic acid by an engineered Thermoanaerobacterium aotearoense with broad substrate specificity. Biotechnol Biofuels 6:124

12. Wang Q, Chen T, Zhao X, Chamu J (2012) Metabolic engineering of thermophilic Bacillus licheniformis for chiral pure D-2,3-butanediol production. Biotechnol Bioeng 109:1610-1621

13. Wang Q, Ingram LO, Shanmugam KT (2011) Evolution of D-lactate dehydrogenase activity from glycerol dehydrogenase and its utility for D-lactate production from lignocellulose. Proc Natl Acad Sci USA 108:18920-18925

14. Kovacs AT, van Hartskamp M, Kuipers OP, van Kranenburg R (2010) Genetic tool development for a new host for biotechnology, the Thermotolerant Bacterium Bacillus coagulans. Appl Environ Microbiol 76:4085-4088

15. Bosma EF, van de Weijer AHP, Daas MJA, van der Oost J, de Vos WM, van Kranenburg $R$ (2015) Isolation and screening of thermophilic bacilli from compost for electrotransformation and fermentation: characterization of Bacillus smithii ET 138 as a new biocatalyst. Appl Environ Microbiol 81:1874-1883

16. Coorevits A, Dinsdale AE, Halket G, Lebbe L, de Vos P, Van Landschoot A et al (2012) Taxonomic revision of the genus Geobacillus: emendation of Geobacillus, G. stearothermophilus, G. jurassicus, G. toebii, G. thermodenitrificans and G. thermoglucosidans (nom. corrig., formerly 'thermoglucosidasius'); transfer of Bacillus thermantarcticus to the genus as G. thermantarcticus; proposal of Caldibacillus debilis gen. nov., comb. nov.; transfer of G. tepidamans to Anoxybacillus as A. tepidamans and proposal of Anoxybacillus caldiproteolyticus sp. nov. Int J Syst Evol Microbiol 62:1470-1485
17. Cripps RE, Eley K, Leak DJ, Rudd B, Taylor M, Todd M et al (2009) Metabolic engineering of Geobacillus thermoglucosidasius for high yield ethanol production. Metab Eng 11:398-408

18. Van Spanning RJ, Wansell CW, Reijnders WN, Harms N, Ras J, Oltmann LF et al (1991) A method for introduction of unmarked mutations in the genome of Paracoccus denitrificans: construction of strains with multiple mutations in the genes encoding periplasmic cytochromes c550, c551i, and c553i. J Bacteriol 173:6962-6970

19. Yudkin MD (1987) Structure and function in a Bacillus subtilis sporulationspecific sigma factor: molecular nature of mutations in spollAC. J Gen Microbiol 133:475-481

20. Boyle NR, Reynolds TS, Evans R, Lynch M, Gill RT (2013) Recombineering to homogeneity: extension of multiplex recombineering to large-scale genome editing. Biotechnol J 8:515-522

21. Van Kranenburg R, Van Hartskamp M, Heintz E, Anthonius J, Van Mullekom E, Snelders J (2007) Genetic modification of homolactic thermophilic Bacilli. WO Patent WO/2007/085,4432007

22. Angelov A, Li H, Geissler A, Leis B, Liebl W (2013) Toxicity of indoxyl derivative accumulation in bacteria and its use as a new counterselection principle. Syst Appl Microbiol 36:585-592

23. Lücking G, Stoeckel M, Atamer Z, Hinrichs J, Ehling-Schulz M (2013) Characterization of aerobic spore-forming bacteria associated with industrial dairy processing environments and product spoilage. Int J Food Microbiol 166:270-279

24. Stoeckel M, Abduh S, Atamer Z, Hinrichs J (2014) Inactivation of bacillus spores in batch vs continuous heating systems at sterilisation temperatures. Int J Dairy Technol 67(3):334-341

25. Fleming AB, Tangney M, Jørgensen PL, Diderichsen B, Priest FG (1995) Extracellular enzyme synthesis in a sporulation-deficient strain of Bacillus licheniformis. Appl Environ Microbiol 61:3775-3780

26. Wang JJ, Greenhut WB, Shih JCH (2005) Development of an asporogenic Bacillus licheniformis for the production of keratinase. J Appl Microbiol 98:761-767

27. Jones SW, Tracy BP, Gaida SM, Papoutsakis ET (2011) Inactivation of $\sigma F$ in Clostridium acetobutylicum ATCC 824 blocks sporulation prior to asymmetric division and abolishes $\sigma \mathrm{E}$ and $\sigma \mathrm{G}$ protein expression but does not block solvent formation. J Bacteriol 193:2429-2440

28. Hols P, Ramos A, Hugenholtz J, Delcour J, De Vos WM, Santos H et al (1999) Acetate utilization in Lactococcus lactis deficient in lactate dehydrogenase: a rescue pathway for maintaining redox balance. J Bacteriol 181:5521-5526

29. Sambrook J, Fritsch EF, Maniatis T (1989) Molecular cloning: a laboratory manual, 2nd edn. NY Cold Spring Harbor Press, Cold Spring Harbor

30. Rhee MS, Kim JW, Qian Y, Ingram LO, Shanmugam KT (2007) Development of plasmid vector and electroporation condition for gene transfer in sporogenic lactic acid bacterium Bacillus coagulans. Plasmid 58:13-22

31. Schaeffer AB, Fulton MD (1933) A Simplified method of staining endospores. Science 77:194

\section{Submit your next manuscript to BioMed Central and take full advantage of:}

- Convenient online submission

- Thorough peer review

- No space constraints or color figure charges

- Immediate publication on acceptance

- Inclusion in PubMed, CAS, Scopus and Google Scholar

- Research which is freely available for redistribution

Submit your manuscript at

www.biomedcentral.com/submit
C Biomed Central 